\title{
A qualitative investigation of parental attitudes and needs for sexual health education for children with autism in Romania
}

\author{
Roland H. Gergely ${ }^{\mathrm{a}, *}$, Alina S. Rusu ${ }^{\mathrm{a}, \mathrm{b}}$ \\ aDoctoral School "Education, Reflection, Development”, Babes-Bolyai University, Sindicatelor 7 \\ Street, 400029, Cluj-Napoca, Cluj, Romania \\ ${ }^{c}$ Faculty of Animal Sciences and Biotechnologies, University of Agricultural Sciences and Veterinary \\ Medicine, Calea Mănăștur Street, 400372, Cluj-Napoca, Romania
}

\begin{abstract}
Parents play an important role as primary educators in the sexual education of children diagnosed with autistic spectrum disorder (ASD). This current study investigates by using a qualitative approach the attitudes and needs of parents regarding the sexual health education (SHE) of their ASD children. A sample of $\mathrm{N}=19$ parents with ASD children and adolescents was included in the study. Data were collected with an online questionnaire (with 11 items referring to aspects of sexual health education). The answers were analyzed by performing qualitative content analysis. The results indicate that most of the parents are open towards sexual health education for their ASD children starting at 8-12 years and, if possible, embedded in therapeutic programs. Parents expressed that they encounter difficulties regarding the communication and recognition of signs of interests of their children towards sexuality. The majority of parents expressed willingness towards participation to parental SHE programs.
\end{abstract}

Keywords: sexual health education; autistic spectrum disorder; parental attitudes and needs

\section{Introduction}

Sexuality and sexual health education (SHE) are two of the most important and difficult subjects in the context of disability. This is because sexual development and behavior can have an impact on the quality of life of people with special needs and their formal and informal social networks. In order to implement a successful SHE program for persons with special needs, such as people with autism spectrum disorder (ASD), several authors and practitioners recommend to take into account a series of individual and social factors. One of these factors is represented by the attitudes and knowledge of sexual education of the parents. Hence, identifying the parents' attitudes in regards to sexuality in general, as well as their attitudes regarding sexual education in the family setting in particular, can be considered a good starting point to develop an intervention SHE program not only for the ASD children and adolescents, but also for a program that can prepare the parents to offer objective and correct sexual education information and guidance to those who might require it, i.e. their children.

The aim of the present study is to identify the attitudes and the needs of parents of children and adolescents with ASD in regards to their sexual health education, having in mind the fact that in Romania, at the moment of performing this research, we could not identify other studies that have addressed this topic. Another focus of the current study is to investigate the attitudes and knowledge obtained in the childhood of the participants regarding sexuality, all of these in the context of their socio-demographic background.

\footnotetext{
* Corresponding author.

E-mail address: gergelyrolland@gmail.com
} 
DSM IV (APA, 1994) presents autism as a pervasive developmental disorder. Additionally, DSM V (APA, 2013) brings a couple key changes in regards to ASD. For example, in DSM V (2013), the Rett's syndrome was excluded from the ASD category. In terms of diagnosis criteria, DSM V (APA, 2013) combines the fields of communication and social interaction, the number of criteria required for diagnosis, includes varying levels of language ability, and, moreover, it increases the specificity and the accuracy of the diagnosis. According to DSM V, ASD is a developmental disorder of the nervous system, which affects the entirety of one's personality; this leads to an atypical neurocognitive development of the person in question, which will have an effect on the entire duration of their lives. Because of these aspects, people with ASD may experience difficulties in some areas of life, such as usage of language, communication based on reciprocity, mental capacity and social interactions (APA, 2013).

\subsection{Sexual development and sexual behavior of children and young adults with ASD}

Sexual development is seen as a complex process that includes sexuality in relation to the self and others. Sexuality comprises a variety of physical, emotional and social interactions. It includes sexual norms, attitudes, knowledge, values and behaviors, and it refers to the autonomy, physiology and biochemistry of the sexual response system. Sexuality implies thoughts, feeling, behaviors, relations, roles, identity and personality (Travers, 2010). Sexual health is often defined as “...the social, physical, mental wellbeing in relation to sexuality; it does not imply only lack of disease, dysfunction or infirmity. Sexual health implies a positive and respectful approach of sexuality and sexual relationships and also the possibility to have secure and gratifying sexual experiences with no constraints, discrimination or violence" (WHO, 2010, p.3). Moreover, "every person that is responsible with providing sexual and relationship related education (...) must be trained and must receive continuing education in order to be sure that the information and counseling that they provide is accurate, scientific validated, suitable and lacking discrimination, gender preconceptions or stigma" (WHO, 2010, p.8).

Similar to other types of children with special needs, children with ASD grow and mature through various steps of their individual development. Every step of our lives brings changes on the physical level and psychosocial requests that must be meet in order to develop sexual health. Sexual development is often associated with normal development; still, people with developmental conditions go through the same sexual developmental steps as they mature. This concept might be difficult to be accepted by some providers and care takers, given the tendency to see people with developmental disabilities as being children (Ballan, 2012).

Autism characteristics interfere with the ability of adolescents and young adults to develop meaningful social relations that are needed to develop sexual/intimate relationships (Stokes, 2007). The most revealing difficulty is given by deficits at level of their social skills, such as lack of nonverbal communication, avoidance of visual contact, low abilities of theory of mind and low levels of response flexibility. The low levels of decision-related skills might complicate the ability to maintain daily details of a relationship, like date initiation or remembering plan. Emotional instability that usually leads to intense or displaced feelings and the lack of awareness of the other person response can challenge the formation and the dynamic of an existent relationship. Sensorial sensibility, like the inability to tolerate touch or other physical sensations, sound sensibility or issues related to texture of foods, can also make romantic dates problematic (Perry, 2009). Understanding the ways in which general population experience romantic intimacy is based on the perception and values of people with typical development; such conclusions can be, however, irrelevant or very little meaningful for people with ASD, because they experience and value romantic intimacy in different ways and degrees (Travis \& Sigman, 1998). Müller (2008) reported that young adults with ASD, on one hand, they experienced isolation feelings, difficulty in the initiation of social interactions, but on the other hand, they 
also wished to experience greater romantic intimacy and more social connections. These results challenge the hypothesis according to which people with ASD are not interested in having any intimate relationship or that they do not care about the social functioning of the world around them. Several recent sstudies indicate that people with ASD are interested in being involved in a romantic relationships. In a longitudinal 20 years study, Farley et al. (2009) asked 41 parents of adult people with ASD about their perceptions and expectations regarding their offspring's involvement in sexual and romantic relationships. Among the parents of ASD adult offspring that were not involved in a romantic relationship at the moment of interviews, $44 \%$ thought that their son or daughter would want to have a romantic relationship.

\subsection{Parental attitudes towards sexual health education of children with special needs}

Sexual health education (SHE) is defined in the literature as a continuous process of gathering information and development of attitudes, beliefs and values during a lifetime. This process comprises several dimensions: sexual development, sexual health, interpersonal relationships, affection, emotion and thoughts, intimacy, body image and gender roles (SIECUS, 2009). Therefore, SHE does not refer only to sexual behavior itself, but it covers other domains of individual and social functioning, including aspects of community integration. In terms of SHE providers, the main responsibility for sexual health education of children teenagers with ASD is considered to fall on parents as primer educator, who most frequently report a lack of professional and material support (Melissa, 2016; Ballan, 2012); Nichols \& BlakeleySmith, 2009). Ballan (2012) shows that parents recognize their role as main providers of sexual education for their children and confirmed their need to be helped in providing it. Parents received information about how their children learned more efficiently and suggested that similar interventions in the future should use technological interfaces with captivating and individualized content (Ballan, 2012). In a focus-group research (Nichols \& Blakeley, 2009), parents recognized that people generally tend to associate sexuality and disability in a negative manner, as opposed to more positive associations they make between these concepts in the case of neurotypical individuals (Nichols \& Blakeley-Smith, 2009). Parents of children with high intellectual and social abilities were more able to think of romantic relationships as a possibility, compared parents of young people with limited intellectual abilities. All parents, regardless of age or the level of intellectual capacity of their children, expressed that they wish their children to have satisfying relationships as they become adults, and some concerns that their daughter or son will not succeed on their own (Nichols \& Blakeley-Smith, 2009). They also expressed concern not only regarding the beginning of puberty and adolescence, but also for their own parental ability to provide the needed support to successfully manage the challenges associated with sexuality. These results are in line with previous research indicating that parents of children with disabilities are concerned about the vulnerability of their children in terms of potential abuse and about misinterpretations of the children's sexual behavior interpretations by other persons, including neurotypical peers (Ruble \& Dalrymple, 1993; Stokes \& Kaur, 2005). Parents report that they often feel lonely in their efforts to educate their children with ASD about their sexual development, although they are aware of their roles as primary educators (Lehan et al., 2016).

The studies presented above point towards the common aspect that parents of children with ASD face difficulties regarding sexual education of their children. Also, the parents are willing to discuss about their concerns and express the need to receive support from experts in the field of SHE.

\section{Methodology}

\subsection{Objective}

The aim of this study is to identify by using a qualitative approach (thematic content analysis) the attitudes and the needs towards sexual health education of 
parents with ASD children. The specific objectives of the study are to identify the level of preparedness regarding SHE of parents with children diagnosed with ASD, and to investigate the attitudes and their expressed needs of towards the aspects that should be addressed when providing sexual health education in the family (with guidance and consultancy from experts in the field, if needed). The following research questions were formulated in order to perform a qualitative content analysis of parental reflections: How do parents with ASD children react when it is necessary to talk with their children about sexuality?; What are the needs of parents with ASD children regarding the SHE of their children?; How do parents of ASD children envision the ways the formal SHE should be performed (in Romania)?; What general recommendations have the parents for sexual education of children with ASD?, and Why do parents think that sexual health education is important or not for their children?

\subsection{Participants}

A number of 19 parents from Romania were included in this study. The main inclusion criteria were to be a parent of ASD children and/or adolescents (up to 18 years) and to be willing to discuss aspects related to Sexual Health Education. Parents were speakers of Romanian language and came from different counties from Romania: București, Brașov, Cluj, Covasna, and Iași. Almost all respondents (84.2\%) were women, while only $15.8 \%$ were men. Regarding their level of education, $42.1 \%$ of respondents had bachelor studies, $15.8 \%$ completed a master's degree, $15.8 \%$ were graduates of high schools and the rest of the parents had other types of studies (i.e. primary school).

\subsection{Instrument}

For the investigation of the SHE-related attitudes, knowledges and needs of parents, a questionaire developed based on the existent literature on the matter was used. The questionaire included specific questions that reflected the five research questions, plus items allowing the gathering of demographic information. The questionaire starts with informing the participants regarding the study and then is followed by four questions/demographic items: age, gender, level of education of the respondends. After the demographic items, a number of 11 questions allowed the collection either quantitative responses (5-point Likert scale), or qualitative reflections (open questions) on several aspects related to SHE, as they follow: (1) How important do you think sexual education for children with ASD is?, (2) Why do you think sexual education is/is not important for your child?, (3) Did you receive sexual education during childhood? (answers yes or no), (4). How useful they think sexual education that you had received during childhood was? (5-point Likert scale, where 1 irrelevant and 5 - very useful), (5). At what age do you think children with special educational needs should begin sexual health education? (the answer included the possibility of choosing from different group ages: 4-6 years; 6-8 years; 8-12 years; 12-16 years; $16-18$ years; $18+$ years), (6). Wold you be willing to participate in a class/workshop for the parents that comprises themes from sexual education? ("yes" or "no" answers), (7). How do you react when your ASD child has a question about sexuality? (open question), (8). Please assess on a scale from 1 to 10 your level of preparedness regarding sexual education for your ASD child, (9). What are your needs regarding formal sexual education for ASD children / what information do you wish the ASD children should receive in formal SHE programs (in schools and/or ONG where take place different therapeutic and/or educational programs). At this question parents had to describe their expectations, needs regarding their children sexual education. In the next question (10), parents were asked to answer how they imagine sexual education for people with disabilities in general. Parents had to describe their opinion about the matter of the question. In the last question (11), the participating parents were asked to offer recommendations for parents regarding the sexual health education for ASD children. 


\subsection{Procedure}

The responses were collected in October 2020 - January 2021 with an online Google form questionnaire. The sampling was based on convenience, by selfselection obtained by the "chain" or "snowball" method (Clark-Carter, 2010), with the help of social media platforms, online groups dedicated to parents and by sharing the add with non-governmental organizations that have a history of collaboration with the Department of Special Education at Babes-Bolyai University (e.g. Autism Transylvania Association Cluj-Napoca, Crystal Children Association Brasov). Parents have initially received a message with the invitation to participate in a study regarding aspects about sexuality and sexual education in Romania for children with ASD and a link towards the study. The participation agreement was received from them, after they were provided a short description of the study and information regarding the safety conditions and privacy of the personal data. The full completion of the questionaires took about 15 minutes. The participants had the option to quit the process of data collection at any moment. The participating parents received an email adress created for the purpose of the study that they could contact the authors for any questions or other clarifications.

\subsection{Data analysis}

A qualitative design was used in this exploratory research. The collected data were qualitatively analised based on the content stucturing and themes identification principles, codes and codes categories inside the themes, following the steps from the content analysis guide (Erlingsson \& Brysiewicz, 2017). Hence, the written answers offered by the parents (reflections) were analyzed using the qualitative content analysis technique according to the combined logic (deductive and inductive) contributing to minimization of data loss. In the combined procedure analysis begins with a few main codes, secondary codes being inductively formed from the given text (Erlingsson și Brysiewicz, 2017). The answers to the items where the answers were offered on a form of Likert-point values were analyzed in a descriptive manner.

\section{Results}

The results are structured based on the research questions.

\section{How do parents with children diagnosed with ASD react when they have to talk with their children about sexuality?}

Our data indicate that almost none of the parents in the current sample had received questions from their children about sexuality. Some of the parents stated that they might have not realized if their child asked about sexuality, or manifested sings of curiosity about sexuality in different ways. Knowing that the thinking ability of children is an abstract one, the questions may be formulated in an indirect way, on their level of communication. Parents indicated in their reflections that they should be able to identify these signs of interest and/or questions coming from their ASD children and try to formulate adequate answers, according the their levels of comprehension. The codes identified in the process of content analysis of the parental answers were grouped in three categories as indicated in Table 2: simple communication (adapted for proper understanding), verbalization ability of the child, and parental encouragement.

Table. 1 Codes and categories of the answers to the research question 1

\begin{tabular}{l|ll}
\hline Theme & Category & Codes \\
\hline $\begin{array}{l}\text { Parents' } \\
\text { reaction when } \\
\text { their children }\end{array}$ & $\begin{array}{l}\text { Simple } \\
\text { communication } \\
\text { (adapted based }\end{array}$ & $\begin{array}{l}\text { "I try to answer so that he can understand" N.N. } \\
\text { he can understand" M.M. }\end{array}$ \\
\hline
\end{tabular}




\begin{tabular}{|c|c|c|}
\hline $\begin{array}{l}\text { have sexuality } \\
\text { related } \\
\text { question (s) }\end{array}$ & $\begin{array}{l}\text { on the level of } \\
\text { comprehension) } \\
\text { The ability of } \\
\text { child to } \\
\text { verbalize }\end{array}$ & $\begin{array}{l}\text { "My child is nonverbal" C.M. } \\
\text { "He hasn't asked yet, he has mental disability, probably } \\
\text { he doesn't understand yet" V.A. } \\
\text { "My child is nonverbal, so there were no question from } \\
\text { him" N.D. } \\
\text { "He is nonverbal" M.M. } \\
\text { "My child is } 4 \text { years old, but surely I would help and } \\
\text { advise him" C.R. } \\
\text { "I would react positively, I would answer if he would ask } \\
\text { me anything about sexuality" M.B. } \\
\text { "Of course. I encourage my boys to ask questions and I } \\
\text { always avoid mocking them if they are curious about } \\
\text { views and opinions about sexuality. If I don't have an } \\
\text { answer, we search for opinions together, usually online" } \\
\text { G.P. } \\
\text { "I do encourage them to be interested about sexuality, } \\
\text { because I want to help them" G.D. }\end{array}$ \\
\hline
\end{tabular}

As it can be seen in Table 1, some parents express openness toward talking about sexuality with their ASD children, if possible. Nearly one third of the parents (7 out of $19)$ indicated that their child is nonverbal.

\section{What are the needs of parents with ASD children regarding the sexual health education of their?}

Within the reflections provided by the parente, we have identified 5 categories of codes: sexual health, sexual abuse, protection against sexual transmission diesease, puberty and self control (Table 2).

Table 2. Codes and categories identified by analyzing the answers to the question number 2

\begin{tabular}{|c|c|c|}
\hline Theme & Category & Codes \\
\hline $\begin{array}{l}\text { Parental } \\
\text { needs } \\
\text { regarding } \\
\text { SHE for } \\
\text { their ASD } \\
\text { children }\end{array}$ & $\begin{array}{l}\text { Protection } \\
\text { against } \\
\text { infections with } \\
\text { sexual } \\
\text { transmission } \\
\text { Puberty and } \\
\text { sexuality } \\
\text { Self control }\end{array}$ & $\begin{array}{l}\text { "Gender identity" G.M. } \\
\text { "What is allowed and what it is not, masturbation and it's effects" } \\
\text { N.D. } \\
\text { "About gender differences, how children are made and intimate } \\
\text { hygiene..." M.M. } \\
\text { "Sexual abuse prevention." V.A. } \\
\text { "How to recognize situations with sexual connotation" N.N. } \\
\text { "Abuse" G.D. } \\
\text { "Contraception methods, prevention of sexual abuse from students" } \\
\text { G.M. } \\
\text { "Everything, especially how important is to protect yourself from } \\
\text { sexual transmission diseases" C.R. } \\
\text { "To protect themselves" N.N. } \\
\text { "Sexually transmitted diseases" M.A. } \\
\text { "Infection disease, hygiene, protection" G.D. } \\
\text { "Risks of an unprotected sexual contact" A.D. } \\
\text { "Puberty" C.M. } \\
\text { "To better understand what happens in his body at puberty" N.N. } \\
\text { "To control their moods as much as they can" C.M. }\end{array}$ \\
\hline
\end{tabular}

3. How do parents of ASD children envision SHE? 
Two categories of codes were identified: adaptation of SHE information and methods to their levels of comprehension and delivery of sexual health education in a similar manner to the programs targeting the neurotypical peers, i.e. without taking into account the existence of disability (Table 3).

Table 3. Categories and codes identified through the analysis of the answers to question number 3

\begin{tabular}{|c|c|c|}
\hline Theme & Category & Codes \\
\hline $\begin{array}{l}\text { How do } \\
\text { parents of } \\
\text { children } \\
\text { diagnosed } \\
\text { with ASD } \\
\text { imagine } \\
\text { sexual } \\
\text { education? }\end{array}$ & $\begin{array}{l}\text { Sexual health } \\
\text { education } \\
\text { adapted on their } \\
\text { level of } \\
\text { comprehension }\end{array}$ & $\begin{array}{l}\text { "According to diagnosis, age" V.A. } \\
\text { "I would like it that she would be understood by them as much as } \\
\text { possible" C.M. } \\
\text { "It must be adapted to their mental age, level of comprehension. } \\
\text { All information should be adapted to this context" N.N. } \\
\text { "Same as for anyone else, but more explained" B.A. } \\
\text { "Explained according to their level of comprehension" D.R. } \\
\text { "I think that they need it to be clearly explained by stories, } \\
\text { images" M.M. } \\
\text { "Same as in a typical context, but the topics and the approach } \\
\text { must be adapted to their level of comprehension. In other words } \\
\text { with many exemplifications." A.D. } \\
\text { "A normal one, similar to others" C.R. } \\
\text { "Same as the one offered in real life to others, without taking in } \\
\text { account disability" A.N. } \\
\text { "Even if the child is typical or with special needs, it is important } \\
\text { that he/she receives correct information about human body, sex } \\
\text { and sexuality, about love and feelings and presented in a proper } \\
\text { manner. There are many frustrations for adolescents and adults } \\
\text { with autism that come from not knowing or not recognizing some } \\
\text { normal changes in their body and in maturing process." G.P. }\end{array}$ \\
\hline
\end{tabular}

As we can see in Table 4, most of the parents state that sexual health eduation (topics, methods) should be adapted to the level of comprehension of the ASD children.

\section{What do parents reccomend for the sexual health education of their ASD} children?

One third of the participating parents described and suggested how SHE should be performed, i.e. examples of methods and instruments that can be used for sexual education of ASD children (Table 4). Some of the parents wrote that SHE is nedeed, but they did not offer any suggestion or recommendation. There are also parents who believe that SHE should consist of a disscusion between the teacher and the student, while others said that sexual education shoud be performed as a therapy, considering it as a more ellaborated process, not just a simple discusion. A very small number of parents consider that sexual education is the school's responsability. 
Table 4. Categories and codes identified through the analysis of the answers to the question number 4

\begin{tabular}{|c|c|c|}
\hline Theme & Category & Codes \\
\hline $\begin{array}{l}\text { What } \\
\text { recommendation } \\
\text { do you have for } \\
\text { the sexual } \\
\text { education of } \\
\text { children with } \\
\text { ASD? }\end{array}$ & $\begin{array}{l}\text { Relevant } \\
\text { topics in } \\
\text { sexual } \\
\text { education } \\
\text { context }\end{array}$ & $\begin{array}{l}\text { "To talk more and advise students and their parents in schools" } \\
\text { C.M. } \\
\text { "To have a conversation with a teacher and nothing more" C.M. } \\
\text { "It is important that the information is structured, concrete } \\
\text { examples, to use images" N.N. } \\
\text { "Sexual education to be performed as therapy." M.B. } \\
\text { "As a method, the use of images and graphics when is possible it is } \\
\text { recommended for people with ASD that have a good visual } \\
\text { intelligence." G.P. } \\
\text { "Choosing the appropriate language." A.D. } \\
\text { "Depends on every child. He/She must understand why they can } \\
\text { have sex, how, with whom, consequences and so on" G.B. } \\
\text { "First, I think it would be beneficial to start with development and } \\
\text { formation of gender identity. Then with intimacy, because most } \\
\text { teenagers with ASD have a compulsive masturbating behavior" } \\
\text { G.M. } \\
\text { "When, where and how many times they can release hormonally and } \\
\text { other things based on necessities" O. L. } \\
\text { "It has to be explained that every human being is different and that } \\
\text { we have physiological needs and we shouldn't have shame feelings } \\
\text { "J. }\end{array}$ \\
\hline
\end{tabular}

5. Why do parents think sexual education is/is not important for their ASD children?

Four categories of codes emerged from the qualitative analysis of the parents' reflections: sexual education to prevent the risk of abuse, rights to SHE, mental health and management of the interpersonal relationships (Table 6).

Table 6. Categories and codes identified in the qualitative analysis of the answers to question number 5

\begin{tabular}{|c|c|c|}
\hline Theme & Category & Codes \\
\hline $\begin{array}{l}\text { Why do } \\
\text { parents } \\
\text { think that } \\
\text { sexual } \\
\text { education } \\
\text { is/is not } \\
\text { important } \\
\text { for their } \\
\text { ASD } \\
\text { children? }\end{array}$ & $\begin{array}{l}\text { Sexual education } \\
\text { as a right to } \\
\text { education } \\
\text { Sexual education } \\
\text { as mental health }\end{array}$ & $\begin{array}{l}\text { "How to recognize situation with sexual connotation" NN. } \\
\text { "To be capable to make the difference between abuse and } \\
\text { normality" M. } \\
\text { "It is important because these children most of them are sexually } \\
\text { abused" G.M. } \\
\text { "For every child sexual education is important." D.A. } \\
\text { "Because he has the right to develop in a healthy manner" JA. } \\
\text { "It is a right of everyone, the right to education." AD } \\
\text { "To better understand what happens in his body." NN. } \\
\text { "Sexual education should teach them to manage their emotions, } \\
\text { moods and to know how to react to different situations." N.D. } \\
\text { "It is important in her development, in the changes and needs that } \\
\text { come over the years." MB. } \\
\text { "It helps him to de-stress." MM. } \\
\text { "Education provides the right information about the changes that } \\
\text { appear in the adolescent organism, it helps the child to know his } \\
\text { body." G.P. } \\
\text { "For health" OL. } \\
\text { "Hormones give excitement moods" C.M. }\end{array}$ \\
\hline
\end{tabular}




\begin{tabular}{l|ll}
\hline $\begin{array}{l}\text { Sexual education } \\
\text { for interpersonal } \\
\text { relationships }\end{array}$ & $\begin{array}{l}\text { "How to relate to others." N.N. } \\
\text { "To teach them how to react in such situations." A.N. } \\
\text { education helps them to develop empathy and respect" G.P. }\end{array}$ \\
& $\begin{array}{l}\text { "For societal integration he needs knowledge regarding sexual } \\
\text { education" M.M. }\end{array}$ \\
\hline
\end{tabular}

Another question addressed to the parents was about the level of importance of SHE is for their ASD children. A number of 15 parents (78.9\%) considered that SHE is very important for their children, 3 of parents $(15.8 \%)$ have answered that SHE is important, and one person $(5.3 \%)$ of the respondents considered that SHE is not at all important. It is important to mention that the person who answered that sexual health education is not important has also expressed the opinion that sexual education cannot be considered a form of education ("Because I don't think of it as education" C.M.). However, almost all the parents $(94.7 \%)$ that participated in the study consider that sexual health education has an important role in the lives of their ASD children.

Parents were asked whether they had received sexual education during childhood. The results showed that only $6(31.6 \%)$ of respondents have received sexual education in their childhood, while most of participants (13 respondents, $68.4 \%$ ) did not receive any form of sexual education during childhood. Those parents that indicated that they have received sexual education during childhood were asked how useful do they think it was. Less than half of these parents considered that the form of SHE that they have received was useful (6 parents).

The next question referred to the age the parents think it is optimal to start sexual education for their ASD children. Results indicate that 5.3\% of participants think sexual education should begin at 6-8 years old, $42.1 \%$ at $8-12$ years, $26.3 \%$ at $12-16$ years, $26.3 \%$ at $16-18$ years, and $10.5 \%$ of the parents consider that sexual education should start after the age of 18 years. Parents were asked to evaluate their own level of preparedness in order to talk about sexuality with their ASD children. The results showed that $52.6 \%$ of the parents think that they are prepared, $26.4 \%$ of them think they are prepared but they have some domains and themes where they need to get more information, while $21 \%$ of the parents think that they are not prepared at all to address sexuality-related topics with their ASD children.

In the last question, parents were asked if they would be willing to participate in a class/workshop that would be organized for parents on topics related to SHE. The majority of the parents (78.9\%) answered "yes", while $21.1 \%$ of the respondents answered "no".

\section{Discussions}

The aim of this study was to identify by using a qualitative approach the attitudes and the needs towards sexual health education for parents with ASD children. Even though the sample was a relatively small one (19 parents of ASD children and adolescents), the results of this exploratory study indicate a diversity of attitudes and personal values regarding sexual health education for children with ASD. Literature points toward the fact that attitudes and personal values can act as barriers against sexual education (Dyson \& Smith, 2012), so we consider that it is important to investigate these aspects before implementing SHE parental programs.

The first research question targeted the parental reactions when their children had questions or expressed signs of interest about sexuality. The results indicate that most of the parents are open to answer these types of questions coming from their children. If the child is not expressing interest or it is not able to communicate, parents, in their roles as primary educators, are the ones that have the responsibility to start a conversation on the topic. Therefore, providing parents with optimal theoretical and procedural SHE knowledge can increase the quality of communication between parents and children on sensitive, yet vital, aspects of individual and family quality of 
life. Literature shows there is a lack of information for parents and care providers regarding sexual education for nonverbal children.

The second research question referred to the needs of parents regarding the sexual education for their ASD children. By analyzing the results, we have identified five categories of codes: sexual health, sexual education as a protective factor against sexual abuse, protection against sexual transmission infections, puberty and selfcontrol. The third question completes the second one, by referring to how parents envision SHE for their children. Some of the parents stated that SHE must be adapted to children's level of development, the type of disability, while other stated that SHE should be provided in a similar way to all the children and adolescents, regardless the existence of special needs. Based on the diagnostic criteria of autism (APA, 2013), it is acknowledged that sexual education cannot be made without adapting the content to the needs of the recipients. The adaptation of content to the needs, interests and level of understanding applies both to typical and non-typical developed children.

The content analysis of the recommendations from parents regarding sexual education for their ASD children revealed the following three categories: the way sexual education is performed, themes that should be addressed in sexual education from the parental perspective, and when is the appropriate moment sexual education should begin. The answers indicated that the majority of parents considered that the optimal age interval for SHE is 8-12 years, and, that, having in mind the special needs of their ASD children, they would prefer an embedding of SHE in a therapeutical approach. In line with this, literature indicates that SHE program with therapeutic components are already being implemented, one of them being based on the PLISSIT model (Annon, 1976).

In 1976, Jack Annon developed the PLISSIT model as a conceptual scheme for treating sexual problems (Annon, 1976). As indicated by the acronym, the model is divided in five levels: Permission, Limited Information, Specific Suggestions and Intensive Therapy. Taking into consideration the parents' recommendations in our study, this model could be adapted in sexual education for people with special needs. The first level in PLISSIT is permission, where the client needs permission in order to talk about his/hers sexual problems. If we adapt this model on the sexual education for ASD persons, we can observe that it is relevant to the needs expressed by the participating parents, because they stated that they feel that their children need encouragement and permission to speak and ask questions about sexuality: "I encourage my ASD boys to ask questions and I always avoid to mock them if they are curious to learn about views or opinions. If I don't have an answer right away, we search together for opinions, usually on the internet" G.P. On the second level of PLISSIT, i.e. the limited information, which means that the beneficiaries receive limited and specific information regarding the sexual topics. This type of limited and clear information would allow to fit the knowledge to the level of development and understanding of the ASD children, as indicated by the parents in our study: "Sexual education should be provided as in a typical context, just that the themes' approach must be adapted to their level of comprehension. That being said, with many clear exemplifications" A.D. The third level of Annon's model (1976) refers to specific suggestions, where the beneficiaries receive specific information and tasks for certain problems. In the case of the needs expressed by the participating parents, these problems would be sexually transmitted infections, recognition of risky situations, e.g. potential sexual abuse etc. The fourth level of PLISSIT is the intensive therapy, where the person that provides sexual education refers the beneficiaries to other persons specialized in mental health. In the context of SHE for ASD children, this level can represent the whole setting of the SHE process, e.g. "Sexual education should be made as therapy" M.B.

Overall, the results support the fact that the participating parents are aware of the importance of sexual health education for their ASD children, event though only few of the parents do consider that the sexual education that they have themselves received in the childhood was useful later on. Another important results is that most of parents think of themselves as being ready to talk about sexuality topics with their children, thus we can say that they perceive themselves as potential primary 
educators, and some of them consider that they need further preparation in certain domains or themes $(26.4 \%)$. A percent of $79 \%$ of the respondents would participate to a class/workshop that targets themes of sexual health education.

In terms of limitation, we mention the low number of the participants, which may be explained by the sensitive subject of the study, i.e. sexuality and sexual education. Although the link to the questionnaire was distributed online to several social media channels, the participants may have not been enough motivated to answer the because of the topic of the research. However, the results are promising and valuable in terms of allowing the identification of specific categories that can be later on converted in items of a new instruments, as well as in terms of the willingness expressed by the parents to participate in SHE parental programs. A dimension that was not specified by the parents was the one related to the gender of children in connection to the needs for sexual education; none of the participants mentioned if the education must include specific themes for girls or boys based on their development or if parents are concerned regarding risks associated to sexual behavior depending on the genders. This dimension will be addressed in future studies.

\section{References}

1. American Psychiatric Association. (1994). Diagnostic and statistical manual of mental disorders (4th edition). Arlington, VA: American Psychiatric Publishing.

2. Annon, J. (1976) The PLISSIT Model: A Proposed Conceptual Scheme for the Behavioral reatment of Sexual Problems. Journal of Sex Education and Therapy. 2 (1), 1-15 https://doi.org/10.1080/01614576.1976.11074483.

3. Ballan, M. S. (2012). Parental perspectives of communication about sexuality in families of children with autism spectrum disorders. Journal of Autism and Developmental Disorders, 42(5), 676-684. https://doi.org/10.1007/s10803-011-1293-y

4. Ballan, M. S. (2011). Parental perspectives of communication about sexuality in families of children with autism spectrum disorders. Journal of Autism and Developmental Disorders, 42(5), 676-684. https://doi.org/10.1007/s10803-011-1293-y

5. Dyson, S., \& Smith, E. (2012). "There are lots of different kinds of normal": Families and sex education-styles, approaches and concerns. Sex Education, 12, 219-229. doi:10.1080/14681811.2011.609053

6. Education and treatment in human sexuality: the training of health professionals. Report of a WHO meeting. (1975). World Health Organization technical report series, (572), 5-33.

7. Erlingsson, C., \& Brysiewicz, P. (2017). A hands-on guide to doing content analysis. African journal of emergency medicine : Revue africaine de la medecine d'urgence, 7(3), 93-99. https://doi.org/10.1016/j.afjem.2017.08.001

8. Farley MA, McMahon WM, Fombonne E, Jenson WR, Miller J, Gardner M, Block H, Pingree CB, Ritvo ER, Ritvo RA, Coon H. (2009). Twenty-year outcome for individuals with autism and average or near-average cognitive abilities. Autism Research, 2(2), 109-118. doi: 10.1002/aur.69.

9. Melissa Lehan, M., Loew, N., Gonzalez, A., Tykol, H., \& Christensen, T. (2016). Parent Perceptions of Sexual Education Needs for Their Children With Autism. Journal of pediatric nursing, 31(6), 608-618. https://doi.org/10.1016/j.pedn.2016.07.003

10. Müller, E., Schuler, A., \& Yates, G. B. (2008). Social challenges and supports from the perspective of individuals with Asperger syndrome and other autism spectrum disabilities. Autism : the international journal of research and practice, 12(2), 173-190. https://doi.org/10.1177/1362361307086664

11. Nichols, S, \& Blakeley-Smith, A (2009). "I'm not sure we're ready for this ...": Working with families toward facilitating healthy sexuality for individuals with autism spectrum disorders. Social Work in Mental Health, 8, 72-91. http://dx.doi.org/10.1080/15332980902932383.

12. Perry N (2009). Adults on the Autism Spectrum leave the nest: Achieving Supported Independence: Jessica Kingsley Publishers 
13. Ruble, L. A., \& Dalrymple, N. J. (1993). Social/sexual awareness of persons with autism: a parental perspective. Archives of sexual behavior, 22(3), 229-240. https://doi.org/10.1007/BF01541768

14. Sexuality Information and Education Council of the United States SIECUS (1996). Issues and answers. Fact sheet on sexuality education. SIECUS report, 24(6), 1-4.

15. Stokes, M., Newton, N., \& Kaur, A. (2007). Stalking, and social and romantic functioning among adolescents and adults with autism spectrum disorder. Journal of autism and developmental disorders, 37(10), 1969-1986. https://doi.org/10.1007/s10803-006-0344-2

16. Stokes, M. A., \& Kaur, A. (2005). High-functioning autism and sexuality: a parental perspective. Autism : the international journal of research and practice, 9(3), 266-289. https://doi.org/10.1177/1362361305053258

17. Travers, J., \& Tincani, M. (2010). Sexuality Education for Individuals with Autism Spectrum Disorders: Critical Issues and Decision Making Guidelines. Education and training in autism and developmental disabilities, 45, 284-293.

18. Travis, L.L. and Sigman, M. (1998), Social deficits and interpersonal relationships in autism. Ment. Retard. Dev. Disabil. Res. Rev., 4: 65-72. https://doi.org/10.1002

19. Byrne, B. M. (1984). The general/academic self-concept nomological network: A review of construct validation research. Review of Educational Research, 54, 427-456

20. Byrne, B. M., \& Worth Gavin, D. A. (1996). The Shavelson model revisited: Testing for the structure of academic self-concept across pre-, early, and late adolescents. Journal of Educational Psychology, 88, 215-228.

21. Leary, M.R., Tangney, J.P. (2003). Handbook of self and identity. New York: Guilford Press. 